\title{
ANALISA ONTOLOGI DAN EPISTEMOLOGI HADIS \\ PERSPEKTIF IBN TAIMIYAH
}

\author{
Achmad Fageh \\ Fakultas Syariah dan IImu Hukum Universitas Islam Negeri Sunan Ampel \\ DPK pada Univeristas Islam Lamongan (UNISLA) \\ Email : achmadfageh@gmail.com
}

\begin{abstract}
Abstrak
Beragamnya pendapat ulama dalam menyikapi hadis-hadis Nabi terkait klasifikasi hadis mutawatir-ahad, menyebabkan terjadinya perbedaan ijtihadiyah dalam memahami isi atau kandungan hadis sehingga terjadi penegasian pengamalan antara satu hadis dengan hadis lainnya; baik itu oleh ahli kalam, ahli sufi dan ahli hadis sendiri. Akar perbedaan itu bila ditelusuri berpangkal pada perbedaan paradigma masing-masing ulama terhadap hadis. Dari fenomena di atas penulis berupaya mengkaji Pemikiran Hadis Ibn Taimiyah dalam menyikapi problemalitas keragaman pemahaman hadis dari aspek ontologis dan epistemplogis. Berangkat dari sini maka pokok masalah yang menjadi pembahasan utama adalah, bagaimana pandangan ontologis-epistemologis Ibn Taimiyah terhadap kedudukan hadis, juga signifikansi dan orisinalitas pemikirannya terhadap studi hadis. Metode penelitian yang penulis gunakan dalam penelitian ini adalah deskriptif-analisisreflektif, yaitu memaparkan secara komprehensif mengenai pemikiran Ibn Taimiyah dari data yang ada, kemudian dianalisis dan melahirkan pemahaman inklusif, baik aspek ontologis, aspek epistemologis. Selain itu hasil penelitian ini mengidentifikasi perbedaan pemahaman hadis antara beberapa ulama, membuka wacana baru tentang bagaimana cara membaca atas redaksi teks hadis, kemudian apa yang dianggap tidak maqbul dan tidak siap konsumsi atau pun sebaliknya, ternyata berstatus maqbul dan siap saji untuk dijadikan pedoman dalam kehidupan serta patut untuk dikonsumsi atau diamalkan.
\end{abstract}

Kata kunci : Orisinalitas, Signifikansi Hadis dan Ibn Taimiyah

\section{PENDAHULUAN}

Terlepas dari dikotomi inkar al-sunnah (pengingkar sunnah) dan nashir alsunnah (penyelamat sunnah), hadis Nabi sudah menjadi 'sunnah' tersendiri dalam praktik sekalipun tidak sepenuhnya. Maka studi atau kajian terhadap hadis akan terus dilakukan, bukan saja oleh umat Islam, tetapi oleh siapapun yang berkepentingan terhadapnya. 
Berbeda dengan ayat-ayat al-Qur'an yang semuanya dapat diterima, hadis tidak semuanya dapat dijadikan sebagai acuan atau hujjah. Hadis ada yang dapat dipakai ada yang tidak. Di sinilah letak perlunya meneliti hadis. Agar dapat meneliti hadis secara baik diperlukan antara lain pengetahuan tentang kaidah dan atau metodenya.

Diskursus mengenai hadis merupakan salah satu hal yang sangat krusial dan berbau kontroversial dalam studi hadis kontemporer. Hal ini boleh jadi disebabkan oleh adanya suatu asumsi bahwa hadis Nabi secara teologis-normatif tidak mendapatkan garansi dari Allah Swt., sebagaimana yang telah dijelaskan dalam firman-Nya. ${ }^{1} \mathrm{Di}$ samping itu, problem otentisitas dipandang sangat urgen karena erat kaitannya dengan pandangan teologis mayoritas umat Islam yang menganggap hadis Nabi Saw. memiliki peran yang sangat strategis dalam rangka revitalisasi syariat Islam. Tidaklah berlebihan jika kemudian Wahbah al-Zuhaili' berpendapat, bahwa al-Qur'an lebih membutuhkan hadis dari pada sebaliknya. ${ }^{2}$

Bila melihat periodisasi sejarah hadis yang meliputi', 1) masa pewahyuan dan pembentukan, 2) masa pemantapan dan pembatasan riwayat, 3) masa penyebaran riwayat, 4) masa penulisan dan pembukuan, 5) masa penyaringan dan pemikiran, 6) masa penggabungan dan penerbitan, dan 7) masa penjabaran dan pembahasan, maka Ibn Taimiyah hidup pada masa ke tujuh ini. ${ }^{3}$

Dalam sejarah, masa ini merupakan masa hancurnya kekhalifahan Abbasiyah yang ditandai dengan munculnya madrasah-madrasah hadis yang berdiri di Mesir, India dan Saudi Arabia. ${ }^{4}$ Dalam kondisi inilah Ibn Taimiyah (661-728 H./1263-1328 M.), seorang tokoh paling terkemuka dari kalangan kaum Hanbali ${ }^{5}$ muncul dan fokus perhatiannya pada studi hadis sebagai sumber ajaran Islam setelah al-Qur'an yang harus diyakini dan diamalkan oleh umat Islam.

Di antara yang menunjukkan bahwa hadis merupakan sumber tasyri' dan wajib diikuti adalah firman Allah Swt. yang artinya "apa yang diberikan Rasul kepadamu

${ }^{1}$ Q.S. al-Hijr (15), hlm. 9

2 Mustaqim "Teori Sistem Isnad Otentisitas Hadis Menurut Perspektif M.M Azami" dalam Wacana Studi Hadis Kontemporer, Hamim Ilyas dan Suryadi (ed.) (Yogyakarta: Tiara Wacana, 2002), hlm. 68 hlm. 452

${ }^{3}$ M. M. Abu Zahw, al-Hadis wa al-Muh\}addisuun (Beirut: Da'r al-Kita'b al-'Arabi', 1984),

4 T. M. Hasbi ash-Shiddiqy, Sejarah dan Pengantar Ilmu Hadis (Jakarta: Bulan Bintang, 1980), hlm. 127.

${ }^{5}$ Abu al-Hasan Ali al-Nadawi, Syaikhul Islam Ibn Taimiyah, terj. H. M. Qadirun Nur, cet. ke-1 (Solo: Pustaka Mantiq, 1995), hlm. 40 
maka terimalah dia, dan apa yang dilarangnya bagimu maka tinggalkanlah". ${ }^{6}$ Ibn Kas $\}$ ir mengatakan, maksud ayat ini adalah segala apapun yang diperintahkan oleh Nabi Saw. wajib dikerjakan dan segala apa yang dilarangnya wajib ditinggalkan. Nabi Saw. hanya memerintahkan yang baik dan melarang yang buruk saja. ${ }^{7}$ Jadi berdasarkan petunjuk ayat tersebut, hadis merupakan salah satu sumber ajaran Islam yang wajib dijadikan landasan hukum.

Dalam hal ini hadis merupakan penjelas bagi al-Qur'an. ia merinci apa yang disebutkan oleh al-Qur'an dalam garis besarnya saja, membatasi apa yang perlu dibatasi, dan mengkhususkan apa yang disebutkan oleh al-Qur'an secara umum. ${ }^{8}$ Hadis berfungsi sebagai 'penopang dan penyempurna' al-Qur'an dalam menjelaskan hukuk-hukum syara'. Keduanya merupakan satu kesatuan dalam kaitannya dengan kepentingan istidlal dan dipandang sebagai sumber pokok.

Kalau berbicara tentang sunnah, pada dasarnya sunnah Nabi berfungsi menjelaskan hukum-hukum dalam al-Qur'an yang pada umumnya berbentuk secara global. Allah Swt. menerapkan hukum dalam al-Qur'an adalah untuk diamalkan, karena pengamalan itulah letak tujuan yang digariskan. Dengan demikian, dapatlah dimengerti bahwa kebanyakan umat Islam memahami sunnah sebagai penafsir al-Qur'an dalam praktik.

Dalam kacamata Ibn Taimiyah hadis maupun sunnah adalah searti, yakni semua yang terjadi pada Nabi setelah kenabiannya, baik dari segi perkataan, perbuatan, dan ketetapannya. Sebagian khabar Nabi dan sebagian sirah nya sebelum kenabiannya dapat dikategorikan sebagai sunnahnya, seperti bartahannus di gua Hira' dan akhlak-akhlaknya yang mulia. Semua itu disebutkan dalam kitab hadis, akan tetapi hal-hal yang berlangsung sebelum kenabian tidak dapat diambil sebagai syariat sehingga yang diwajibkan bagi umat Islam adalah mengimani, dan mengamalkan apaapa yang bersumber dari Nabi setelah kenabiannya. ${ }^{9}$

Ibn Taimiyah menyatakan bahwa kedudukan hadis terhadap al-Qur'an adalah pertama, sebagai sumber kebenaran kedua setelah al-Qur'an dalam memahami ajaran Islam, dan kedua, sebagai penjelas yang menerangkan makna-makna yang

6 .S. al-H\}asyr (59): hlm. 71.

7 Ibn Kas|l'r, Tafsi'r al-Qur'an al-Azim, Juz IV, cet. ke-1 (Beirut: Maktabah al-Nu'r al'Ilmiyyah, 1992), hlm. 336

8 Must\}afa' al-Siba'i', al-Sunnah wa Maka'natuha' fi' Tasyri' al-Islami (Beirut: alMaktabah al-Islami', 1975), hlm. 380 hlm. 6-10.

${ }^{9}$ Ibn Taimiyyah, Majmu" Fata'wa' Syaikh al-Isla'm Ah\}mad Ibn Taimyiyah (t.k.: t.p, t.t.), 
terkandung dalam al-Qur'an. ${ }^{10}$

Sebagaimana dijelaskan di atas, bahwa Ibn Taimiyah muncul pada saat terjadinya penyimpangan pemikiran tentang sumber ajaran Islam, ia hadir untuk pemecahan hal tersebut. Ibn Taimiyah mengarahkan kegiatannya melalui semangat keagamaan yang literal 'kembali pada al-Qur'an dan hadis' dengan sikap kritis untuk membuka pintu ijtihad yang tertutup. ${ }^{11}$ la sering berselisih pendapat dengan penguasa demi mempertahankan pendapat yang diyakininya. Tulisan-tulisannya banyak berisi kritikan pedas terhadap persoalan umat Islam yang diyakininya tidak sesuai atau menyimpang dari al-Qur'an dan hadis.

Pemikiran Ibn Taimiyah dalam bidang hadis cukup kritis terutama pada hadishadis yang dianggap lemah atau palsu, ${ }^{12}$ demikian pula Ibn Taimiyah terlalu ketat (tasyaddud) berpegang teguh pada hadis-hadis sahih, untuk menjaga kemurnian ajaran salaf ia tidak suka menggunakan ta'wil.

Contoh sikap kritisnya ini antara lain kritiknya atas hadis Muslim tentang penciptaan alam semesta selama tujuh hari di mulai hari sabtu dan di akhiri hari jum'at. Hadis ini dalam pandangan Ibn Taimiyah ${ }^{13}$ dinilai lemah karena bertentangan dengan al-Qur'an, ${ }^{14}$ bahwa Allah Swt. menciptakan langit dan bumi beserta isinya itu selama enam hari.

Sejalan dengan perkembangan pemahaman hadis dan sunnah, selanjutnya term hadis dan sunnah tidaklah sama walaupun mayoritas ulama hadis berusaha mengidentikkannya. Semua ulama yang mengetahui definisi suatu lafaz dari segi bahasa dan istilah, tidaklah akan mengatakan bahwa lafaz hadis identik dengan sunnah. Masing-masing dari lafaz tersebut mempunyai makna sendiri-sendiri walaupun pada suatu segi ada persamaannya.

Namun, pada akhir abad II Hijriah terjadi penyempitan makna sunnah sehingga dikhususkan untuk sunnah Rasul. Hal ini karena Imam Syafi'i mengajak kepada masyarakat untuk mengamalkan hadis ahad serta mendahulukan hadis dari tradisi yang sudah berlaku di masyarakat. Sejak itulah hadis dan sunnah mempunyai satu

${ }^{10}$ Muhammad Abu' Zahrah, Ibn Taimiyyah: Haya'tuhu wa Ara'uhu (Kairo: Da'r al-Fikr al-Arabi', t.th.), hlm. 454.

11 Ibn Taimiyyah, Muqaddimah fi' Us\}u'l al-Tafsir (Kuwait: Da'r al-Kari'm, 1971), 93-94

12 T. M. Hasbi ash-Shiddiqy, Sejarah..., hIm. 230

13 Ibn Taimiyah, Majmu" al-Fata'wa', Juz XVIII (t.k.: al-Maktabah al-'Arabiyyah alSu'u'diyyah, 1398 H.), hlm. 18.

${ }^{14}$ Q.S. al-Furqa'n (25): 29; al-Sajdah (32): 4; Qa'f (50): 38; al-Hadid (57): 4. 
makna. ${ }^{15}$

Ibn Taimiyah menyatakan, bahwa klasifikasi hadis yang diformulasikan oleh ulama hadis tidaklah begitu penting, mengingat bahwa yang menjadi fokus kajian sebenarnya adalah lebih menonjolkan kualitas periwayat dan periwayatannya ketimbang sisi kuantitasnya. ${ }^{16}$

Dalam pandangan Ibn Taimiyah, hadis ahad tidak mempunyai faedah kecuali prasangka dan tetap wajib diamalkan dengan catatan bahwa hadis ahad tersebut termasuk dalam kategori hadis yang memiliki persyaratan diterimanya suatu hadis ( hadis maqbu'l), atau hadis tersebut memenuhi pesyaratan hadis sahih atau hasan ${ }^{17}$ juga karena hadis ahad membawa khabar yang benar. ${ }^{18}$

Jika dilihat dari sisi perkembangan pemikiran, pada masa Ibn Taimiyah ini tumbuh subur berbagai macam agama dan aliran kepercayaan, fanatisme golongan dan mazhab, ahli-ahli fiqih, ahli-ahli kalam, dan para filosof. ${ }^{19}$ Kondisi seperti inilah yang mendorong Ibn Taimiyah untuk membersihkan praktek-praktek keagamaan yang berbau bid'ah dan khurafat untuk kembali pada ajaran salaf.

Penulis menyadari bahwa Ibn Taimiyah dalam studi hadis kurang begitu dikenal, meski demikian terdapat pembahasan tentang pemikirannya terkait kajian hadis. Oleh karena itu penulis merasa termotivasi untuk mengadakan penelitian lebih jauh mengenai pemikiran Ibn Taimiyah tentang studi hadis dari aspek ontologisnya, yakni untuk memberikan jawaban terhadap apa hadis itu dengan ruang lingkup pembahasannya serta penafsiran tentang hakikat realitas dari objek hadis itu, dan dari aspek epistemologisnya, yakni bagaimana hadis itu dapat diterima sebagai sumber ajaran Islam. Berdasar latar belakang di atas, maka penulis mencoba memfokuskan penelitian ini pada beberapa pertanyaan, di antaranya',

1. Bagaimana pandangan ontologis dan epistemologis Ibn Taimiyah terhadap hadis ?

2. Apa signifikansi dan orisinalitas pemikiran Ibn Taimiyah terhadap studi hadis?

${ }^{15}$ Rif'at Fauzi 'Abd al-Mutthalib, Tausiq al-Sunnah fi Qarn al-Sani al-Hijr; Asasuhu wa Ittijahuhu (Mesir: Maktabah Khari'j, 1981), hlm. 19

${ }_{16}$ Pemikiran ini muncul karena Ibn Taimiyah melihat adanya dikotomi antara hadis mutawatir dan hadis ahad.

17 Amru Abdul Mun'im Salim, al-Albani dan Manhaj Salaf, terj. Ahmad Yuswaji, cet. ke1 (Jakarta: Najla Press, 2003), hlm. 102

34.

18 Ibn Taimiyyah, IImu al-H\}adi's (Beirut: Da'r al-Kutu'b al-'Alamiyyah, 1989), hlm. 33-

${ }^{19}$ Ahmadie Thaha, Ibn Taimiyah: Hidup dan Pikiran-pikirannya, cet. ke-1 (Surabaya: PT. Bina IImu, 1992), hlm. 15 


\section{KONSEP DASAR HADIS}

Sunnah atau hadis (perkataan dan kebiasaan Nabi Muhammad Saw.), dalam arti sunnah yang sebenarnya, menunjukkan suatu patokan dari kebiasaan Nabi, sedangkan hadis menunjukkan ucapan Nabi. Tapi keduanya merupakan dasar yang sama dan telah teraplikasi dalam tindakan, perbuatan, dan perkataannya. Hadis telah mencatat dan menceritakan Sunnah Nabi, sebagai bagian dari sejarah terdapat tiga kebaikan dari sunnah, itu mungkin perkataan Nabi yang diaplikasikan dalam tingkah lakunya. Dan hal ini telah menjawab semua pertanyaan yang berhubungan dengan sunnah Nabi, sebuah tindakan dan kebiasaan Nabi dalam fi'il nya, atau kebiasaankebiasaan lainnya (taqri'r).

Dalam kehidupan sehari-hari, sering dijumpai sekelumit masalah ringan yang sering ditanyakan orang lain kepada kita mengenai sesuatu hal yang tidak dimengertinya. Hingga tidaklah mengherankan kiranya ketika suatu waktu kita akan ditanya', "Apa sih Hadis dan Sunnah itu?". Untuk menjawabnya tentunya kita harus menyesuaikannya dengan konteks bahasa dan latar belakang si penanya dengan bahasa yang lugas dan mudah dimengerti.

Memahami hadis tidak cukup dengan mengetahui makna hadis secara terminologi maupun epistemologi yang tata bahasanya telah terukur dengan 11 baik, akan tetapi setidaknya kita memahami makna ontologis dari hadis dan sunnah yang menyangkut nilai-nilai pemahaman kita tentang maksud dari sekelumit tatanan bahasa yang bersumber dari jumhur ulama dan mengejawantahkannya dengan konteks tatanan bahasa kita sendiri. Tentunya dengan tidak mengurangi makna dasar dari hadis dan sunnah itu sendiri.

Sehingga untuk dapat memahami makna ontologis hadis, kita semestinya bisa memahami nilai-nilai dasar yang terkandung dari definisi jumhur ulama agar kita dapat dengan mudah memberikan pengertian kepada siapa saja yang menanyakan tentang hadis dan sunnah menurut apa yang bisa dimengerti, dipahami, agar lebih memudahkan untuk mengamalkannya.

Sering juga terdengar ditelinga kita, bahwa di kalangan minoritas umat Islam ada yang mengingkari keberadaan hadis sebagai sumber ajaran Islam. ${ }^{20}$

20 Menurut Muhammad Abu Zahwu bahwa golongan yang menolak hadis sebagai sumber ajaran agama, terbagi dua golongan: 1) golongan yang menolak hadis secara keseluruhan; dan 2) golongan yang menolak hadis ahad saja. Lihat M.M. Abu Zahwu, al-Hadis wa al-Muhaddisun (Mesir: Matba'ah Misr, t.th.), 21-37. Sedangkan Imam Syafi'i membaginya menjadi tiga: 1) golongan yang menolak hadis secara keseluruhan, baik yang mutawatir maupun yang ahad; 2) golongan yang menolak hadis, kecuali menerimanya jika ada persamaan 
Kenyataan ini membawa pikiran mayoritas Muslim untuk berfikir filosofis guna menemukan pijakan ontologis yang meyakinkan. Pijakan ontologis ${ }^{21}$ akan bermakna jika didukung oleh pijakan epistemologis ${ }^{22}$ yang menggambarkan bagaimana cara pemahaman dan penerimaan hadis yang handal sepanjang zaman.

Dalam pada itu, hadis atau biasa kita dengar dengan kata sunnah -versi ahli fiqih, dalam perjalanannya banyak mengalami berbagai permasalahan yang cukup pelik dan banyak memunculkan kontroversi, baik di dunia Islam sendiri (ahli ushul dan ahli hadis) maupun dunia Barat (orientalis). Hal ini adalah wajar yang esensial dari upaya orang Muslim untuk menyesuaikan doktrin terhadap perubahan keadaan, karena hadis merupakan simbol kewenangan Nabi Saw. dan merupakan sumber kesinambungan dengan masa lalu.

Sunnah pada dasarnya tidak sama dengan hadis. Mengikuti arti bahasanya, sunnah adalah jalan keagamaan yang ditempuh Nabi Saw. yang tercermin dalam prilakunya yang suci. ${ }^{23}$ Sementara hadis bersifat umum meliputi sabda dan perbuatan Nabi Saw. Secara etimologi hadis mempunyai arti jadid (baru), qarib (dekat) dan khabar (warta).

Adapun secara terminologi kata hadis ini berdekatan dengan kata sunnah. Ulama mutaqaddimin membedakan antara sunnah dan hadis, menganggap sunnah sebagai sesuatu yang diambil dari Nabi Saw. tanpa membatasi waktu. Sementara hadis adalah segala perkataan, perbuatan atau ketetapan yang disandarkan kepada Nabi Saw. pasca kenabian. Sedangkan ulama mutaakhirin menganggap bahwa sunnah maupun hadis memiliki pengertian yang sama, yaitu segala ucapan, perbuatan atau ketetapan Nabi Saw. ${ }^{24}$

dengan al-Qur'an; dan 3) golongan yang menolak hadis ahad. Lebih jelasnya lihat Abu Abdillah Muhammad bin Idris al-Syafi'i, al-Umm, juz VII (Mesir: Maktabah al-Sya'ab, t.th.), hlm. 250367

${ }^{21}$ Ontologi merupakan asas dalam menetapkan batas ruang lingkup objek penelaahan dan penafsiran tentang hakikat realitas (metafisik) dari objek ontologi tersebut. Lihat Jujun S. Suriasumantri, Filsafat IImu Sebuah Pengantar Populer (Jakarta: Pustaka Sinar Harapan, 1982), hlm. 23.

22 Epistemologi merupakan asas cara bagaimana materi pengetahuan diperoleh dan disusun menjadi satu tubuh pengetahuan. Jujun S. Suriasumantri, Filsafat IImu, 24

${ }^{23}$ Pemakaian kata sunnah juga digunakan oleh ulama hadis dan ulama usul fiqih terhadap perbuatan sahabat, seperti sunnah sahabat dalam mengkodifikasikan al-Qur'an dan sebagainya.

Terkadang makna sunnah merupakan lawan dari bid'ah, yakni semua perkataan dan perbuatan yang dibuat-buat tentang ibadah, tidak bersumber kepada Nabi atau sahabat. Lihat Muhammad Ajjaj al-Khatib, al-Sunnah Qabl al-Tadwin (Beirut: Dar al-Fikr, 1963), hlm. 14-19.

${ }^{24}$ Muhammad Ajja'j al-Khatib, Ushul al hadits, Ulumuhu wa Musthalahuhu, (Beirut: Da'r al-Fikr, 1989), hlm. 18. 
Selain dua term di atas, ada istilah khabar yang dipandang sama dengan hadis oleh ahli hadis. Oleh karenanya istilah khabar ini mereka gunakan untuk hadis marfu", mawqu'f, dan maqt\}u'. Dengan kata lain, bahwa yang dimaksud dengan khabar ialah segala sesuatu yang diterima dari Nabi, sahabat atau tabi'in. Tetapi sebagian dari mereka membedakan, hadis ialah yang diterima dari Nabi Saw., sedangkan khabar ialah yang menyangkut selain Nabi Saw. Adapun as|ar menurut ulama hadis ialah hadis marfu" dan hadis mawqu'f. Tetapi ulama Khurasan menamakan hadis mawqu'f dengan as|ar, dan hadis marfu" dengan khabar. $^{25}$

Subhi al-Shalih memformulasikan hadis menjadi dua pokok yaitu ilmu hadis riwayah dan ilmu hadis dirayah. IImu hadis riwayah adalah segala sesuatu yang disandarkan kepada Nabi Saw. baik berupa perkataan, perbuatan, ketetapan, sifat Nabi Saw. dan segala sesuatu yang disandarkan kepada para sahabat dan tabi'in. Sedangkan pembahasan yang berkaitan dengan sanad dan matan hadis dimasukkan pada kategori ilmu hadis dirayah. ${ }^{26}$

Dari uraian di atas, maka antara pengertian sunnah atau hadis terdapat perbedaan 'isi', akan tetapi tidak membawa kepada perbedaan prinsip. Singkatnya, secara garis besar, sunnah adalah model kehidupan Nabi Saw. atau dengan kata lain jejak dan langkah Nabi Saw. yang terbentuk melalui tindakan dan ucapannya. Sedangkan hadis adalah berita tentang ucapan, perbuatan, dan hal ihwal Nabi Saw. (peristiwa yang disandarkan pada Nabi Saw.). Terlepas dari perbedaan di atas, istilah sunnah nampaknya lebih mencirikan ulama usul fiqih, sementara term hadis labih banyak di pakai ulama hadis sendiri. Dan perbedaaan arti dari term sunnah maupun hadis, yang jelas keduanya berakhir pada muara yang sama yakni segala sesuatu informasi atau perbuatan Nabi Saw.ISA

\section{ANALISA ONTOLOGI DAN EPISTEMOLOGI HADIS PERSPEKTIF IBNU TAIMIYAH}

Kajian mengenai Ibn Taimiyah ini bukanlah kajian pertama, sebagai salah satu tokoh intelektual dan pembaharu dalam keilmuan Islam. Di Indonesia Ibn Taimiyah menjadi salah satu tokoh hadis yang menarik untuk dikaji pemikirannya. Namun demikian tidak banyak penelitian yang dilakukan oleh peneliti sebelumnya terkait studi hadisnya terutama yang berbentuk Skripsi dan Tesis.

${ }^{25}$ Muhammad Ajja'j al-Khatib, Ushul al hadits, Ulumuhu wa Musthalahuhu, (Beirut: Da'r al-Fikr, 1975), 27-28.

${ }^{26}$ Subhi al-Shalih, Membahas IImu-ilmu Hadis, terj. Tim Pustaka Firdaus (Jakarta: Pustaka Firdaus, 2000), hlm. 101 
Adapun kajian yang berkaitan dengan pemikiran Ibn Taimiyah yang pernah dilakukan oleh peneliti sebelumnya terkait studi hadis di antaranya adalah tulisan Arief Imanullah yang fokus bahasannya adalah pandangan Ibn Taimiyah terhadap hadis ahad dilihat dari implikasi dan konsekuensinya. ${ }^{27}$

Daniel Ramdanulansyah yang fokus kajiannya adalah membahas kehujjahan hadis ahad sebagai landasan dalam masalah akidah. ${ }^{28}$ Selanjutnya adalah pembahasan mengenai dikotomi mutawatir dan ahad perspektif Ibn Taimiyah yang ditulis oleh Khoirul Anwar, ${ }^{29}$ dan penelitian Slamet Priyadi tentang penerapan hadis da'if dalam fada'il al-a'mal. ${ }^{30}$ Juga eksplorasi Agusni Yahya yang kajiannya mengenai pemikiran Ibn Taimiyah terkait otentisitas dan pemahaman hadis-hadis mukhtalif, ${ }^{31}$ bukunya Muhammad Suraji Menghidupkan Sunnah Nabi, ${ }^{32}$ di dalamnya dijelaskan bagaimana memahami sunnah terkait hadis-hadis tanawwu' al-'ibadah menurut Ibn Taimiyah, dan juga kajian pemikiran Ibn Taimiyah terkait al-Qur'an dan metode penafsirannya. ${ }^{33}$

Kajian-kajian di atas adalah kajian tentang corak pemikiran Ibn Taimiyah hanyalah parsial berkisar seputar hadis dha'if, mutawatir-ahad terkait masalahmasalah tertentu, terkait hadis-hadis mukhtalif dan hadis-hadis tanawwu' al-'ibadah. Sedangkan pemikirannya secara umum tentang hadis dan klasifikasinya secara sistematis belum pernah dilakukan. Oleh karena itu penelitian ini melengkapinya.

27 Arief Imanullah, skripsi "Hadis Ahad Menurut Ibn Taimiyah (Tinjauan Implikasi dan Konsekuensi Pemikiran)", Jurusan Tafsir Hadis, Fakultas Ushuluddin, IAIN Sunan Kaijaga Yogyakarta, 2001.

28 Daniel Ramdanulansyah, Skripsi "Kahujjahan Hadis Ahas dalam Masalah Aqidah (Studi Pebandingan antara Ibn Taimiyah dan Muhammad Nasir al-Din al-Albani)", Jurusan Tafsir Hadis, Fakultas Ushuluddin, IAIN Sunan Kaijaga Yogyakarta, 2004

29 Khoirul Anwar, Skripsi "Dikotomi Mutawatir-Ahad (Studi Atas Pemikiran Ibn Taimiyah)", Jurusan Tafsir Hadis, Fakultas Ushuluddin, IAIN Sunan Kaijaga ,Yogyakarta, 2004

30 Slamet Priyadi, Skripsi "Penerapan Hadis Da'if sebagai Fadail al-A'mal Menurut alGazali dan Ibn Taimiyah", Jurusan Tafsir Hadis, Fakultas Ushuluddin, UIN Sunan Kalijaga, Yogyakarta, 2005.

31 Agusni Yahya, Disertasi “Otentisitas dan Pemahaman Hadis-hadis Mukhtalif (Studi Pemikiran Ibn Taimiyyah, 1263-1328 M)", Program Pascasarjana, UIN Sunan Kalijaga, Yogyakarta, 2009.

32 Muhammad Suraji, Menghidupkan Sunnah Nabi, cet. ke-1 (Yogyakarta: Grafindo Litera Media, 2005)

33 Fatimah Tuzzahro, Skripsi "Ibn Taimiyah dan Tafsir al-Kabir", Jurusan Tafsir Hadis, Fakultas Ushuluddin, IAIN Sunan Kalijaga, Yogyakarta, 2001 


\section{PENUTUP}

Ibn Taimiyah adalah Syaikhul Islam, al-Imam Abu al-Abbas Taqiyuddin Ahmad ibn Abd al-Halim ibn Abd al-Salam ibn Taimiyah al-Dimisyqi, seorang ulama besar yang berusaha memperbaiki rakyat dan agama, ahli berbagai disiplin keilmuan. Lidah dan kalamnya sama fasihnya. Beliau telah memberi pelajaran dan fatwa sebelum cukup umurnya 20 tahun.

Karyanya amat banyak. Karena beliau dimusuhi oleh ulama di masanya, beliau difitnah lalu dipenjarakan hingga akhirnya meninggal di dalam penjara. Beliau lahir pada tahun $661 \mathrm{H} / 1263 \mathrm{M}$, dan wafat pada tahun $728 \mathrm{H} / 1328 \mathrm{M}$.

Ibn Taimiyah menyatakan, bahwa antara hadis dan al-Qur'an jelas ada pertalian hubungan yang erat, dan karenanya satu sama lainnya tidak dapat dipisahkan kendatipun antara keduanya bisa dibedakan dari berbagai aspeknya. Hal inilah yang mendasari sikap ontologis dan epistemologis Ibn Taimiyah dalam memandang alQur'an dan sunnah atau hadis sebagai sumber hukum Islam, dan ijtihad merupakan sumber hukum ketiga (peraturan Islam atau kaidah-kaidah yang dirumuskan oleh Muslim yang berilmu).

Kewajiban mengamalkan hadis di samping al-Qur'an, bukan semata-mata karena diperintahkan oleh al-Qur'an dan hadis itu sendiri, melainkan juga disebabkan kebutuhan umat Islam kepadanya sangat besar. Kedudukan al-Qur'an sebagai salah satu alat pengukur (instrument) bagi kebenaran makna suatu hadis, agaknya begitu penting dan karenanya perlu mendapat perhatian serius. Begitupun sebaliknya, hadis sebagai penjelas atau penafsir dari al-Qur'an harus dilakukan penelitian yang cermat agar tidak terjebak pada pemikiran-pemikiran yang picik.

Hadis Nabi pada umumnya diriwayatkan secara zhanny (ahad). Jumlah hadis yang diriwayatkan secara qat'iy terlalu sedikit bila dibandingkan dengan yang diriwayatkan secara qat'iy. Oleh karenanya Ibn Taimiyah menerima hadis ahad sebagai hujjah dalam semua masalah agama termasuk masalah akidah maupun hukum, dengan catatan bahwa hadis ahad tersebut memenuhi persayaratan hadis shahih yang menyebabkan hadis ahad tersebut bisa diterima. Hal ini dikarenakan hadis ahad berfaidah ilmu al-yaqin.

Mengenai syarat-syarat diterimanya hadis ahad sebagai hujjah dalam masalah akidah, Ibn Taimiyah mensyaratkan periwayat yang adil (mukallaf, melaksanakan ketentuan agama dan memelihara muru'ah), dapat dipercaya dalam agama (tsiqah), dikenal jujur dalam periwayatan, (dhabit) dalam arti periwayat mampu memahami 
kemudian menghafalkan serta menyampaikannya kembali dengan baik, dan rangkaian riwayatnya bersambung hingga kepada Nabi. Akan tetapi pada bagian matan Ibn Taimiyah kurang memberikan perhatian yang tegas terhadap pesyaratan adanya matan yang harus shahih. Namun demikian ia juga mengatakan, hadis ahad bisa diterima jika disertai dengan qarinah-qarinah penguat yang menunjukkan keshahihannya. Qarinah tersebut seperti adanya ijma' untuk mengamalkan hadis tersebut, dan umat sepakat mengamalkannya.

Walaupun demikian Ibn Taimiyah bukan berarti sama sekali tidak menyinggung masalah matan. Misalnya tentang hadis yang bertentangan isinya dengan lahir alQur'an, Ibn Taimiyah dapat menerimanya sebagai pen-takhsis, penjelas, pembatas dan penambah isi al-Qur'an. Hanya saja secara metodologi Ibn Taimiyah sama sekali tidak menyinggung kemungkinan adanya hadis yang pada lahirnya telah memenuhi kriteria yang dikemukakannya, tetapi sesungguhnya hadis tersebut bila diteliti lebih jauh ternyata mengandung cacat ('illah) dan atau kejanggalan (syudzudz).

Sikap moderasi, inklusif, akomodatif, praktis serta fleksibel yang ditunjukan lbn Taimiyah dalam menghadapi permasalahan hadis terkait hadis-hadis mukhtalif dan tannawwu' al-'ibadah kiranya dapat dikembangkan dan dimasyarakatkan, dengan harapan dapat mengeliminir pandangan-pandangan picik terhadap pemahaman keagamaan. Dengan demikian, tiada sikap saling menegasikan amalan satu dengan amalan lainnya. Dan diharapkan dapat menciptakan suasana khusuk dalam beribadah, kemudahan dalam melaksanakan ajaran agama, keluwesan sikap dalam berbeda pendapat sehingga terbinanya suatu kerukunan, ketentraman dan keharmonisan dalam berinteraksi sesama intern umat Islam khususnya, dan non-Islam pada umumnya.

Pentingnya sikap akomodatif-kompromistis bagi seseorang sebenarnya bukan hanya dalam bentuk pelakasanaan ibadah yang sebenarnya sama-sama memiliki nilai keutamaan yang sepadan antara satu dengan lainnya. Akan tetapi hendaknya seseorang bersikap akomodatif terhadap pelaksanaan ibadah tertentu yang dilakukan secara berlawanan dengan amalan yang lebih utama.

Bahkan menurut Ibn Taimiyah, terkadang seseorang yang melakukan amalan ibadah tertentu secara berlawanan dengan amalan yang lebih utama, jika disasarkan atas kemaslahatan yang lebih besar, tindakan yang demikian itu dibenarkan dan merupakan sikap yang terpuji. 


\section{DAFTAR PUSTAKA}

Ashur, S.M., (1962), al-Mujtama' al-Misri fi 'Asri al-Salatin al-Mamali, Kairo, Dar alNahdhah al-'Arabiyah

Asqalani al-, (t.t), Nuzhat al-Naz\}ar Syarh\} al-Nukhbah al-Fikr, Semarang, Maktabah al-Munawwar, t.t.

Awad, Mahmud, (1986), Para Pemberontak di Jalan Allah, terj. Alimin dan Raimond, cet. ke-2, Jakarta, Cendekia Centra Muslim

Albani, Muhammad Nashiruddin al-, (2002). Hadis sebagai Landasan Akidah dan Hukum, terj. Moh. Irfan Zein, cet. ke-1, Jakarta, Pustaka Azzam

Muhammad Nasir al-, (1986), al-Hadis Hujjatun bi Nafsihi fi al-'Aqaid wa alAhkam, Kuwait', Dar al-Salafiyah

Amien, Miska Muhammad, (2006), Epistemologi Islam, Jakarta, UI Press

Bagus, Loren, (2002), Kamus Filsafat, cet. ke-3, Jakarta, PT. Gramedia Pustaka Utama

Bahanasawi, Salim Ali al-, (2001), Rekayasa al-Sunnah, terj. Abdul Basith Junaidy, cet. ke-1, Yogyakarta, Ittaqa Press

Bakhtiar, Amsal, (2005). Filsafat Ilmu, Jakarta, PT. Raja Grafindo

Bakry, Hasbullah, (1992), Sistematika Filsafat, Jakarta, Widjaya

Barbour, Ian G. (2002), . Juru Bicara Tuhan', Antara Sains dan Agama, Bandung, Mizan

Bertens, K., (2001),. Ringkasan Sejarah Filsafat, Yogyakarta, Kanisius

Broklenan (ed.), (1980). Carl, History of The Islamic Peoples, London, Routeledge \& Kegen Paul,

Dardiri, A., (1986). Humaniora, Filsafat, dan Logika, Jakarta, Rajawali,

Edwards (ed.), Paul, (1972), The Encyclopedia of Philosophy, New York, Mac Milan Publishing Co.

El Fadl, Khaled Abu, (2003), Speaking in God's Name, England', Oneworld Publications.

Fajri, Rahmat, (1890), “Kajian Historis Pemikiran Teologi Ibn Taimiyah" dalam Esensia,

vol. 1, no. 2, Juli 2000. Farabi, al-, al-Samrah, al-Mardiyyah fi Ba'd alRisalah alFarabiyyah, Leiden', t.p.

Gazalba, Sidi, (1973), Sistematika Filsafat, Pengantar Kepada Teori Pengetahuan, Buku II, Jakarta, Bulan Bintang

Hadi, Muhammad ibn Ahmad ibn Abd al-, (t.t.), al-'Uqud al-Durriyah min Manaqib Syaikh al-Islam ibn Taimiyah, Beirut, Dar al-Kutub al-IImiyah

Hamami M., Abbas, (1982). Epistemologi Bagian I Teori Pengetahuan, Yogyakarta, Fakultas Filsafat UGM

Hassan, A. Qadir, (1983), Ilmu Musthalah Hadis, Bandung, Diponegoro

Hourani, Albert, (1992). A History of The Arab People, New York', A Time Warner Company

Hunnex, Milton D., (2004). Peta Filsafat, Pendekatan Kronologis dan Tematis, Bandung, Teraju

Husain, Abu Lubabah, (2003), Pemikiran Hadis Mu'tazilah, Jakarta, Pustaka Firdaus.

Ibrahim, Muhammad Nur, (t.t), Ilmu Mantiq, cet. ke-4, Surabaya, Maktabah Sa'ad Ibn Nasyir Nabhan.146

llyas (ed.), Yunahar, (1996), Pengembangan Pemikiran terhdap Hadis, cet. ke-1, Yogyakarta, LPPI UMY.

Iqbal, Muhammad, (1960). The Reconstruction of Religious Thought in Islam, Lahore', 


\section{Muhammad Ashraf}

Islahi, Abdul Azim, Economic Conceps of Ibn Taimiyyah, London, The Islamic Foundation, 1988

Jamil, Tariq al-, "Ibn Taimiyya and Syi'i Polemics', The Struggle for Traditionalist

Authority in The Medieval Islam", dalam The Ibn Taimiyya and His Time, Princeton', Princeton University, 8-12 April 2005

Jawziyyah, Ibn Qayyim al-, (1995), 'llam al-Muwaqqi'in, Beirut, Dar Fikr.

Jindan, Khalid Ibrahim, (1994), The Islamic Theory of Government According to Ibn Taimiyah, terj. Mufid, Jakarta, Rineka Cipta

Kamal, Zainun, Kritik Ibn Taimiyah terhadap Logika Aristoteles, Disertasi Doktor, Fakultas Pasacasarjana IAIN Syarif Hidayatullah, Jakarta. 2004

Kamali, Muhammad Hasyim, (1999), The Principles of Islamic Jurisprudence, Selangor, Dar al-Ehsan

Kartanegara, dkk., Mulyadi, (2003), Menyatukan Kembali Ilmu-ilmu Agama dan Umum, Yogyakarta, SUKA Press

, Mulyadi, (2003), Pengantar Epistemologi Islam, Bandung, Mizan

Kasir, Ibn, (1992). Tafsir al-Qur'an al-Azim, Juz IV, cet. ke-1, Beirut, Maktabah alNur al-Ilmiyah,

Kattsoff, Louis O, (1953), Element of Philoshopy, New York', The Roland Press Company

Khan, Qomaruddin, (1983). Pemikiran Politik Ibn Taimiyah, terj. Anas Mahyudin, Bandung, Pustaka.

Khatib, Muhammad Ajjaj al-, (1963), al-Sunnah Qabl al-Tadwi'n, Beirut, Dar al-Fikr

Muhammad Ajjaj al-, (1989), Usul al-Hadis', Ulumuhu wa Mustalahuhu,Beirut, Dar al-Fikr

Kramers (ed.), H.A.R. Gibb dan J.H., (1961). Shorter Encyclopedia of Islam, Jilid III, Leiden', E.J. Brill.

Kuntowijoyo, (1997). Identitas Politik Ummat Islam, Bandung, Mizan , (2003). Metodologi Sejarah, Yogyakarta, Tiara Wacana.

Laoust, Henry, (1997). Nazarriyyat Syaikh al-Islam Ibn Taimiyah fi alSiyasiyah wa alljtima', cet. Ke-1, Cairo', Dar al-Anshar.

, Harun, (1978), Teologi Islam, cet. ke-2, Jakarta, Universitas Indonesia,

Madjid, Nurcholis, "Kontroversi Sekitar Ketokohan Ibn Taimiyah" dalam KKA Paramadina, seri ke-81, tahun VII/1993.

, Nurcholis, Islam dan Doktrin Peradaban, Jakarta, Yayasan Waqaf

Paramadina, 1992Makari, Victor E., Ibn Taimiyyah's Ethics', The Social Factor, ChicoCalifornia', Scholar Press, 1983.

Madkour, Ibrahim, (1995). Aliran dan Teori Filsafat Islam, cet. ke-1, terj. Yudian Wahyudi Asmin, Jakarta, Bumi Aksara.

Mahzar, Armahedi, (2004). Revolusi Integralisme Islam, Bandung, Mizan.

Mu'thi, A. Wahab, (1991), "Kritik Ibn Taimiyah terhadap Tasawuf", Disertasi Doktor Pascasarjana IAIN Syarif Hidayatullah, Jakarta.

Muhadjir, Noeng, (2001), Filsafat Ilmu, Positivisme, Post Positivisme dan Post Modernisme, Yogyakarta, Rake Sarasin.

Muhammad, Sa'ad Shadiq, (t.t), Ibn Taimiyyah Imam al-Sayf wa al-Qalam, KairoMesir', al-Majlis al-A'la al-Syu'un al-Islamiyah,

Mutalib, Rif'at Fauzi Abd al-, (1981), Tausiq al-Sunnah fi Qarn al-Sani al-Hijri Asasuhu wa Ittijahuhu, Mesir, Maktabah Kharij.

Muthahhari, Murtadha, (2002), Pengantar Pemikiran Sadra', Filsafat Hikmah, terj. Tim Penerjemah Mizan, Bandung, Mizan.

Murtadha, (2001). Mengenal Epistemologi, terj. M. Jawad Bafaqih, 
Bandung, Lentera Basritama.

, Murtadha, (1994). Pandangan Dunia Tauhid, terj. Redaktur YBT, Bandung, Yayasan Muthahhari.

Muzairi, (2002). Eksistensialisme Jean Paul Sartre, Sumur Tanpa Dasar Kebebasan Manusia, Yogyakarta, Pustaka Pelajar,

Nadawi, Abu al-Hasan Ali al-, (1995), Syaikhul Islam Ibn Taimiyah, terj. H. M. Qadirun Nur, Solo', Pustaka Mantiq.

Nasution, Harun, (1992), Pembaharuan dalam Islam', Sejarah Pemikirann dan Gerakan, Jakarta, Bulan Bintang.

Nihayah, M., (2002), Filsafat IImu dari Yunani Kuno sampai Modern, Makassar, Berkah Utami.

Oumid, Mas'oud, “Epistemologi Suhrawardi dan Allamah Tabataba'i, Sebuah Perbandingan", Jurnal Al-Huda, Vol. III/No.09, tahun 2003.

Qardawi, Yusuf al-, (1993), al-Sah\}wah al-Islamiyah wa Humum al-Wathan al-'Arabi wa al-Islami, Beirut, Muassasah al-Risalah.

Qasimi, Muhammad Jamal al-Din al-, (1979). Qawaid al Tahdis min Funun Musthalahah al-Hadis, Beirut, Dar al- Kutub al-Ilmiyyah.

Raharjo, Dawam, (1990), “ilmu”, Ulumul Qur'an, Vol. 1, Januari-Maret, M/1410 H.

Rahman, Fazlur, (1982). Islam and Modernity, Chicago', The University of Chicago Press,

Fazlur, (1994). Memahami Islam, Bandung, Pustaka

Romdon, (1996), Ajaran Ontologi Aliran Kebatinan, Jakarta, Rajawali Press.

Rosenthal, Franz, (1997) Knowledge Triumphant', The Concept of Knowledge in Medieval Islam, Leiden', E.J Brill.

Runes (ed.), (1976) Dagobert D., Dictinary Philoshopy, Totowa New Jersey', Little Adam \& Co.

Saefuddin, dkk.,(1998) A.M., Desentralisasi Pemikiran', Landasan Islamisasi, Bandung, Mizan.

Salim, Amru Abdul Mun'im, (2003) al-Albani dan Manhaj Salaf, cet. ke-1, terj. Ahmad Yuswaji, Jakarta, Najla Press.

Shalih, Muhammad Adib, (1399 H), Lamahat fi Ushul al-Hadis, t,k, al-Maktab al-Islami.

Shalih, Subhi al-, (2000) Membahas IImu-ilmu Hadi, Firdaus Jakarta, Pustaka Firdaus.

Shiddiqy, T.M. Hasbi ash-, (1980), Sejarah dan Pengantar IImu Hadis, Jakarta, Bulan Bintang,

Siba'i, Mustafa al-, (1975) al-Sunnah wa Makanatuha fi Tasyri' al-Islami, Beirut, alMaktabah al-Islami,.

Sivan, Emmanuel, (1990) Radical Islam Medieval Theology and Modern, Yale, Yale University,.

Soemargono, Soejono, (1983) Filsafat Ilmu Pengetahuan, Yogyakarta, Nur Cahaya.

Sunoto dkk., (1983) Pemikiran Tentang Kefilsafatan Indonesia, Yogyakarta, Andi Offset

Surachmad, Winarno, (1985), Pengantar Penelitian Ilmiah, Bandung, Tarsito.

Suraji, Muhammad, (2005), Menghidupkan Sunnah Nabi, Yogyakarta, Grafindo Litera Media.148

Surajiyo, (2005), IImu Filsafat Suatu Pengantar, Jakarta; PT. Bumi Aksara.

Suriasumantri, Jujun S., (1996) Filsafat IImu, Sebuah Pengantar Populer, Jakarta, Pustaka Sinar Harapan.

Suryadi, Hamim Ilyas dan (ed.), (2002) Wacana Studi Hadis Kontemporer, Yogyakarta, Tiara Wacana.

Suyuti, Jalal al-Din al-, (1947) Shawn al-Manthiq li Kalam 'an Fann al-Manthiq wa alKala'm, Mesir', Matba'ah al-Sa'adah 
Syafi'i, Abu Abdillah Muhammad bin Idris al-, (t.t), al-Umm, juz VII , Mesir', Maktabah al-Sya'ab.

, Muhammad bin Idris al-, (t.t), al-Risalah, Beirut, Dar al-Fikr

Taimiyah, Ibn, al-'Aqidah al-Wasitiyyah, (t.t), Beirut, Dar al-'Arabiyah , Ibn, (1989), Ilmu al-Hadis, Beirut, Dar al-Kutub al-lamiyah Ibn, Iqtida al-Shirah al-Mustaqim Mukhalafat Ashab al-Jahim, Beirut, Dar

al-Fikr.

al-Suudiyah Ibn, (1398 H), Majmu' al-Fatawa, Juz. XVIII, t.k., al-Maktabah al-Arabiyah Ibn, (1398 H), Majmu' Fatawa, Jilid. II, XX, Beirut, Dar al-Arabiyah. Ibn, (t.t), Minhaj al-Sunnah al-Nabawiyah, Juz 1, Beirut, Dar al-Kutub alllmiyah Ibn, (1971), Muqaddimah fi Usul al-Tafsir, Kuwait, Dar al-Karim al-'llmiyyah Ibn, (1988), Raf'u al-Mala'm 'an al-'Aimmat al-'Ala'm , Beirut, Dar al-Kutub Ibn, (t.t), Shihhat Usul Mazhab Ahl al-Madinah, Mura'ja'ah wa Taqdi'm Ahmad Hjja'zi' al-Siqa', (t.t), Beirut, Maktabah al-Saqafah al-Diniyyah.

Tafsir, Ahmad, (2002), Filsafat Umum, Bandung, Rosdakarya

Thaha, Ahmadie, (1992), Ibn Taimiyah', Hidup dan Pikiran-pikirannya, cet. ke-1, Surabaya, PT. Bina IImu

Thahhan, Mahmud al-, (1979), Tasyir Musthalah al-Hadis, Beirut, Dar al-Qur'an alKarim,

Wardani, (2003), Epistemologi Kalam, Yogyakarta, eLKiS

Yazdi, Muhammad Taqi Misbah, (2003), Buku Daras Filsafat Islam, terj. Musa Kazhim, Bandung, Mizan,

Yoesqi, Mohd. Isom, (2006), Inklusivitas Hadis Nabi Muhammad SAW. Menurut Ibn Taimiyyah, Jakarta, Pustaka Mapan

Zahrah, Muhammad Abu, (1963), al-Ta'rif bi Ibn Taimiyah, dalam Ushul al-Fiqh allslam wa Mahrajan al-Imam Ibn Taimiyah, Kairo, al-Majlis al-A'la li Ri'ayat alFunun wa al-Adab wa al-Ulum al-ljtima'iyah.

Zahwu, M.M. Abu, (1984), al-Hadis wa al-Muhaddisun, Beirut, Dar al-Kitab al-Arabi.

Zarkasyi, Hamid Fahmy, (2005), "Worldview Sebagai Asas Epistemologi Islam", Jurnal Islamika, th. II, no.5, April-Juni,

Zubair, Anton, (1990) Bakker dan Charis, Metodologi Penelitian Filsafat, Yogyakarta, Kanisius. 